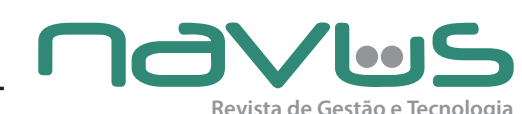

Revista de Gestão e Tecnologia

\title{
Conhecer e empreender: um estudo sobre a utilização de artefatos gerenciais em organizações contábeis
}

\author{
Luiz Carlos Marques dos Anjos, Paulo da Cruz Freire dos Santos, Luiz Carlos \\ Miranda, Daniel José Cardoso da Silva, Rommel de Santana Freire
}

\section{RESUMO}

A dificuldade dos contadores em perceber sua atividade profissional como empresarial tem levado a gestão das empresas contábeis a ser conduzida, muitas vezes, de maneira informal. 0 resultado é o não desenvolvimento e aplicação de técnicas formais de avaliação do desempenho organizacional. Existem no Brasil 76.267 escritórios de contabilidade e, em Alagoas, onde esta pesquisa foi realizada, 756 organizações contábeis, sendo $86,24 \%$ constituídas como empresas individuais. Essas organizações são responsáveis pela gestão de bens patrimoniais de seus clientes, e pela produção de informações econômicas e financeiras que auxiliam na solução de problemas. Sabe-se que através da gestão contábil pode-se utilizar técnicas que auxiliam a gestão do negócio e avaliam seu desempenho. A utilização dessas técnicas no próprio negócio pode indicar um perfil empreendedor no empresário contábil, na medida em que este se mostra atento às informações que retratem uma imagem mais fiel da sua empresa. Este estudo teve como objetivos investigar, analisar e evidenciar como os contadores estão utilizando ferramentas contábeis na gestão de seus próprios negócios. Na coleta de dados utilizouse um questionário, disponibilizado aos contadores através de meio eletrônico e mala-direta. A amostra foi por conveniência e totalizou 89 respondentes. 0 tratamento estatístico dos dados aplicou técnicas de análise descritiva, testes $\chi 2$ e exato de Fisher. Os resultados mostraram pouca utilização ou conhecimento de ferramentas gerenciais contemporâneas. Os respondentes não consideram este fator crucial para ampliar seu mercado e na gestão de seus negócios costumam utilizar critérios retirados de sua experiência profissional ou que envolvam a gestão de caixa.

Palavras-Chave: Artefatos gerenciais. Organizações contábeis. Contabilidade Gerencial. Empreendedorismo. 


\begin{abstract}
The difficulty of accountants to manage their firms as an enterprise has led the management of accounting firms to be conducted often informally. The result is the not development and application of formal techniques for measure organizational performance. Brazil has 76,267 accounting firms and the State of Alagoas, where this research was conducted, 756 accounting organizations, which $86.24 \%$ are constituted as individual companies. These organizations are responsible for managing the assets of their clients, and the production of economic and financial information to assist in troubleshooting. It is known that the accounting management techniques can be used to help manage business and evaluate its performance. Using these techniques, in the business itself, may indicate an entrepreneurial profile in accountants, as deep as they prove to be aware of information that reflects a more accurate picture of company. This study aimed to investigate, analyze and disclosure how the accountants are using accounting tools in managing their own businesses. Data collection used a questionnaire available on electronic media and sent by direct mail. The sample was by convenience and it was heard 89 respondents. The statistical analysis used measures of position, the $\chi 2$ test and Fisher's exact test. The results show little use or knowledge of contemporary management tools. The respondents do not consider this a crucial factor to expand their market and to manage their businesses they have being used criteria involving the management of cash or deducted from their own experience.
\end{abstract}

Keywords: Managerial artifact. Accounting organizations.Managerialaccounting.Entrepreneurship. 


\section{INTRODUÇÃO}

A utilização de artefatos gerenciais contábeis vem ganhando destaque em diversas pesquisas como é o caso das conduzidas por Anjos, Miranda e Silva (2010), Oyadomary (2008), Soutes (2006), Frezatti (2005), Lucena (2004), Oliveira (2001), etc. Essas pesquisas discutiram diversos aspectos dentro desta temática, como a oferta e demanda de informações contábeis, indicadores contemporâneos vs. tradicionais, aplicação específica de ferramentas para empresas de portes distintos (como é o caso das micro e pequenas empresas), etc.

No entanto, são poucos os relatos na literatura, sobre a utilização de tais indicadores dentro de organizações contábeis. Qual a razão disso, pois o contador é o profissional que possui, além da habilitação, o conhecimento dos conceitos e aplicações de informações que poderiam ser úteis na gestão das organizações? Será que ele não as utiliza?

A necessidade de tomar decisões em períodos de tempo cada vez menores pode acabar levando os gestores a decidir, baseados exclusivamente em suas experiências ou mesmo na intuição, o que pode dificultar a condução do negócio (MIRANDA et al., 2007).

De acordo com o Conselho Federal de Contabilidade (2011), no Brasil, há um total de 76.267 escritórios de contabilidade. Em Alagoas existem 756 organizações contábeis, sendo 652 (86,24\%) constituídas na forma de empresa individual, o que representa menos de $1 \%$ do total destas entidades no país.

A importância dessas organizações mostra-se no momento em que as empresas de menor porte não podem manter um departamento formal de contabilidade e necessitem terceirizar este serviço, contratando contadores externos.

A necessidade, mesmo que legal, dos serviços prestados por tais empresas leva a pensar sobre problemas que sua descontinuidade poderia gerar para a sociedade, tendo em vista que a mudança desse prestador de serviços é envolvida por um alto nível de dificuldade de se identificar profissionais que, além de capacitados e disponíveis, passem confiança para seus clientes.

Dessa maneira a utilização do ferramental gerencial que estes profissionais podem oferecer, poderia trazer uma maior confiança não apenas para os clientes, mas para o próprio empreendedor (profissional contábil), que conheceria melhor seu negócio e poderia definir de forma mais assertiva o design do seu negócio.

Surge então a seguinte indagação de pesquisa: estariam os contadores utilizando artefatos contábeis gerenciais na gestão de seus próprios negócios?

A busca de respostas à indagação de pesquisa definiu os objetivos do estudo, a saber: investigar, analisar e evidenciar se os contadores estariam utilizando ferramentas contábeis que se mostram úteis na gestão de seus próprios negócios.

\section{REVISÃO DA LITERATURA}

É reduzido o uso de artefatos gerenciais pelos contadores, entretanto, aqueles que aparentemente utilizam mostram características empreendedoras, aqui se entendendo, o termo empreendedor como 
sinônimo de inovador (DRUCKER, 1993; NAIR; PANDEY, 2006). A partir daí pode-se dizer que um profissional contábil apresenta características empreendedoras se ele for além do usual, e buscar novas ferramentas que indiquem sua diferenciação e que o destaquem entre os demais na sua área de atuação. Essa diferenciação estará ligada à utilização de artefatos gerenciais.

\subsection{O uso da informação contábil}

Diz Umbelino (2008) que os últimos anos têm apresentado não mais a revolução industrial, mas sim a revolução da informação. Esta revolução é evidente através da constante busca por saber cada vez mais, e com um imediatismo cada vez maior. A utilização de informações confiáveis e tempestivas é imprescindível para a avaliação do desempenho empresarial por parte de seus usuários, quer sejam eles gestores, proprietários, credores, clientes, governo e, inclusive, potenciais investidores. Informações com qualidade são necessárias para reduzir a assimetria destas, proporcionando assim, melhores condições para a tomada de decisão por parte dos gestores (LOPES; MARTINS, 2005).

De acordo com o Conselho Federal de Contabilidade (2008) a informação contábil é composta por algumas características qualitativas que a torna útil para seu usuário. Segundo este órgão destacase a compreensibilidade, relevância, confiabilidade e comparabilidade. Além de poder ser prontamente entendida por seu usuário, ser relevante no processo decisório, estar livre de erros e vieses, representar adequadamente as transações e eventos a que se propõe, bem como permitir sua comparação ao passar do tempo, esta informação deve chegar a tempo e completa para aquele que a utiliza. Miranda et al. (2007) afirmam ainda que a informação contábil não deve ter fins exclusivamente fiscais, o que vai de encontro aos resultados de uma pesquisa exploratória desenvolvida por Stroeher e Freitas (2006, p.8) que constataram que "o empreendedor não vê o serviço de contabilidade como uma extensão de sua empresa, e sim como uma obrigação imposta pelo governo com fins arrecadatórios”. Kam (1990) afirma que para ser útil a informação contábil deve ser confiável e relevante, principalmente, porque a contabilidade não servirá apenas para compreender fatos passados, mas sim para desenvolver modelos que permitam prever possíveis resultados futuros.

Quanto à compreensibilidade, McGee e Prusak (1995) afirmam que, muitas vezes, o fornecedor da informação acaba pecando pelo excesso ao oferecer enormes documentos impressos, ou acesso a bancos de dados amplos sem instruções que facilitem a obtenção rápida da informação desejada, tornando-se um obstáculo à sua utilização. Umbelino (2008) diz ainda que uma sofisticação exagerada da informação pode acabar levando a este mesmo resultado. Um exemplo disso é mostrado em um dos resultados da pesquisa de Caneca (2008). Ela identificou que para 39,2\% dos empresários pesquisados, os contadores precisam ainda entregar relatórios diferentes dos atuais, que possam ajudar na gestão do negócio.

Isso pode levar ao que já foi constatado por diversos pesquisadores (CANECA, 2008; MIRANDA et al., 2007; LUCENA, 2004; OLIVEIRA, 2001) ao identificarem que por 
diversas vezes os gestores acabam tomando decisões com base em suas próprias experiências ou mesmo na intuição, o que pode dificultar a condução do negócio e que, de acordo com Miranda et al. (2007), é um fator agravante da taxa de mortalidade de empresas.

Magalhães e Lunkes (2000, p. 35) estabelecem duas premissas para a utilização da contabilidade no processo administrativo de uma organização: ser útil e desejável pelos seus usuários. Assim a informação contábil, ao assumir uma postura gerencial, deve ainda adotar como premissas: planejamento e controle (GARRISON; NOREEN; BREWER, 2007; UENO; CASA NOVA, 2006; MAGALHÃES; LUNKES, 2000; KANITZ, 1977), para que possa atingir o objetivo de subsidiar o processo decisório. Como a gestão possui características específicas para cada tipo de entidade, poderá apresentar menores diferenças em grupos de organizações similares. Como exemplo, pode-se citar o caso das empresas prestadoras de serviço.

\subsection{Organizações contábeis no Brasil e empreendedorismo}

De acordo com Lopes et al. (2007), em todo o mundo, as empresas prestadoras de serviços desempenham importante papel na economia, notoriamente pela geração de emprego e renda, contribuindo para a construção do Produto Interno Bruto (PIB) dos países. Esses mesmos autores dizem ainda que este setor é o maior responsável pelo PIB mundial, e que suas taxas de crescimento de contratação de mão de obra são superiores ao comércio e à indústria.

Buscando-se conceituar serviço pode- se recorrer à Meirelles (2006, p. 130) que entende ser o mesmo "trabalho em processo, ou seja, serviço é trabalho na concepção dinâmica do termo, trabalho em ação".

Laudon e Laudon (1999), ao tratar o assunto, fazem uma abordagem mais voltada à gestão das organizações e afirmam que as empresas prestadoras de serviços apresentam três funções básicas: coordenar as ações de vários profissionais com área de atuação diversificada para o alcance de um resultado comum; interligar as várias partes ou elementos que compõem a organização e interligar a empresa ao seu ambiente externo controlando a fronteira existente entre ambos.

Organizações contábeis são entidades prestadoras de serviços e, portanto, podem ser entendidas segundo as conceituações apresentadas. Para Pereira (2005), no Brasil, elas têm como principal objetivo fornecer informações acerca do patrimônio, além de atender às obrigações tributárias das empresas clientes. Esse mesmo autor afirma que as empresas de serviços contábeis estão estruturadas prioritariamente para emissão de relatórios fiscais. Isso acaba dificultando a percepção dos clientes acerca do diferencial qualitativo entre uma empresa e outra (PEREIRA, 2005).

Com base no que dizem esses autores observa-se que uma organização prestadora de serviços contábeis, por atuar externamente às entidades que a contratam, tem como principal desafio conseguir subsidiar o processo decisório, apresentando informações oportunas.

Para o Conselho Federal de Contabilidade, abordando o aspecto jurídico, as organizações contábeis são classificadas como sociedade, empresário e 
escritório individual (CONSELHO FEDERAL DE CONTABILIDADE, 2009). Adriano et al.(2007) veem-nas como responsáveis pela gestão de bens patrimoniais de seus clientes, bem como pela produção de informações econômicas e financeiras auxiliando na solução de problemas. Thomé (2001), por seu lado, pontua que os serviços contábeis não se limitam à área tributária, antes enfocam a gestão sob uma ótica mais ampla atingindo, inclusive, aspectos intangíveis. Adriano et al. (2007) asseguram ainda que a qualidade destes serviços é guiada pela geração de valor ao cliente, o que demanda conhecimento profundo não apenas de ferramentas gerenciais que possam agregar tal valor, mas de qual é a demanda existente de informação.

Neste aspecto estudos como os de Caneca (2008), Umbelino (2008) e Miranda et al. (2007) evidenciam a ocorrência de desequilíbrio entre a oferta e a demanda de informação contábil. Nestes estudos podem-se identificar alguns achados, como o fato de que os micro e pequenos empresários percebem o contador apenas como provedor de serviços relacionados à obrigações tributárias e sociais, porém, estes mesmos gestores estariam dispostos a pagar mais, caso fossem fornecidas informações efetivamente úteis à tomada de decisão. Além disso, o desenvolvimento de um bom relacionamento pessoal com o cliente pode criar uma percepção de boa qualidade do serviço prestado e, consequentemente, garantir a manutenção do contrato. Aspectos como conhecimento profundo de instrumentos que possam auxiliar a gestão, bom relacionamento interpessoal, marketing, criação e venda de portfólio, dentre outras, podem evidenciar um perfil empreendedor por parte do profissional contábil.

Em relação a perfil empreendedor diversos autores têm tentado chegar a um ponto comum. No entanto, devido as controvérsias e desencontros, Dutra (2002) sugere que se deve, inicialmente, definir a corrente que se deseja estudar: a dos economistas ou a comportamental, que segundo ele, enfoca as características psicológicas e sociológicas do empreendedor. Segundo a visão comportamental o empreendedor é alguém focado em atender a sua necessidade de realização, ou seja, criar ou realizar coisas (MCCLELLAND, 1961). Na óticade muitos economistas, notadamente em Schumpeter (1961) o empreendedor é caracterizado como sendo um empresário capaz de introduzir inovações que podem levar à alavancagem da economia. Sob esse enfoque, no âmbito da gestão de uma organização contábil, o profissional contador deveria utilizar, pelo menos, os conhecimentos basilares da contabilidade a fim de analisar seu desempenho frente aos clientes atendidos, podendo assim, ter uma melhor percepção do custo de atendê-los. Fazem parte deste conhecimento diversos instrumentos de medição de desempenho, também conhecidos como artefatos gerenciais, que poderiam auxiliar este profissional na tarefa de conhecer melhor seu próprio negócio e estabelecer suas estratégias empresariais.

Segundo Porter (1986) existe cinco forças que são importantes no processo estratégico dos empreendimentos empresariais: concorrentes, fornecedores, compradores, produtos ou serviços substitutos e a ameaça de novos concorrentes. 
A atividade de fornecer e interpretar ferramentas gerenciais úteis para os clientes, um elemento estratégico, pode ser aprimorada no momento em que o próprio contador as utiliza em seu próprio negócio, pois poderia de antemão identificar pontos fortes e oportunidades não só dos instrumentos de gestão, mas - principalmente - do processo de implementação deste ferramental.

Pereira (2005), aplicando essas ideias às organizações contábeis, diz que usualmente os contadores não encaram sua atividade profissional como uma atividade empresarial e, em decorrência disto, acabam não atentando para questões como planejamento das atividades, pesquisas de marketing, demandas de mercado, desenvolvimento de estratégias, aprofundamento de conhecimentos variados, etc. Este comportamento leva o profissional contábil a avaliar seu desempenho apenas comparando se "está ganhando" mais, do que na atividade que o mesmo desenvolvia anteriormente, logo não há um conhecimento aprofundado do negócio o que pode acabar por comprometer a continuidade do mesmo. Isso conduz ao que defende Martins (2001) ao afirmar que o ambiente interno, em uma organização contábil, é uma variável crítica para obtenção de sucesso.

\subsection{Artefatos gerenciais contábeis}

De acordo com Oyadomari et al. (2008) têm surgido diversas técnicas para auxiliar a gestão do negócio através da avaliação de desempenho. A utilização de tais artefatos pode caracterizar o perfil empreendedor do empresário contábil, na medida em este está atento às informações que podem apresentar uma imagem mais fiel da empresa. Diz Frezatti (2005), a partir de um estudo que realizou, que em ambientes que são mais instáveis e incertos, poder utilizar ferramentas de planejamento preditivo permitirá que uma organização aumente sua eficiência na busca de maior controle de suas operações. Por outro lado, Soutes (2006) afirma que apesar de existirem diversos fatores facilitadores para o surgimento e utilização de artefatos modernos, pouca mudança tem sido verificada nas práticas de contabilidade gerencial dos dias atuais. A mesma autora diz ainda que diversos pesquisadores propuseram separações das práticas utilizadas quanto à sua abordagem, a saber: tradicionais e contemporâneos. As primeiras se caracterizam por serem menos frequentes, se basearem no orçamento padrão e se vincularem, prioritariamente, ao desempenho financeiro. As segundas destacam-se por serem mais oportunas e aumentar o enfoque em medidas não financeiras. Nesta pesquisa não se fez tal distinção. Neste estudo consideram-se artefatos gerenciais métodos, conceitos e indicadores que possam ser fornecidos pela contabilidade para auxiliar a tomada de decisão.

O Quadro 1 traz uma relação de artefatos utilizados em outras pesquisas e que foram abordados na coleta de dados. Estes instrumentos foram selecionados a partir de pesquisas de Frezatti (2005), Soutes (2006), Lopes et al. (2007), Oyadomari et al. (2008), bem como através de fatos percebidos pelos pesquisadores ao aplicar questionários e em suas experiências profissionais.

Qual informação é útil para a tomada de decisão depende totalmente do usuário 
Quadro 1 - Relação de instrumentos gerenciais abordados na pesquisa

\begin{tabular}{|l|l|}
\hline Custeio direto & Prazo médio de recebimento (PMR) \\
\hline Custeio pleno & Necessidade de imobilização do capital \\
\hline Mark-up & Retorno \\
\hline Preço meta & Risco operacional \\
\hline Custeio por absorção & Ponto de equilíbrio \\
\hline Custeio variável & Centros de atividade/resultado \\
\hline Custeio ABC & Custo de oportunidade \\
\hline Margem de contribuição & Necessidade de capital de giro (NCG) \\
\hline Rentabilidade & Balanced scorecard (BSC) \\
\hline Plano de negócios & Orçamentos \\
\hline
\end{tabular}

Fonte: FREZATTI, 2005; SOUTES, 2006; LOPES et al., 2007; OYADOMARI et al., 2008 e elaboração própria.

dessa informação. 0 processo cognitivo para tal escolha é influenciado por diversos fatores que incluem, não apenas o ramo de atividade e porte da empresa, mas também, a formação do gestor, sua escolaridade e cultura organizacional. Um dos maiores desafios para a contabilidade pode ser formar um portfólio de indicadores que atendam aos anseios dos usuários internos. Nesse caso, de acordo com Marriot e Marriot (2000), existe ainda a dificuldade de se vender tais serviços, pois por mais que os clientes saibam que podem obter benefícios ao contratar serviços gerenciais, não gostam da ideia de ter que pagar mais, mesmo sem saber o tamanho do benefício.

\section{METODOLOGIA}

O universo da pesquisa foi o conjunto das organizações contábeis alagoanas. Por questões de restrições orçamentárias, foi selecionada uma amostra não probabilística, classificada como por conveniência.

Os participantes foram contatados através de mala-direta enviada pelo Conselho Regional de Contabilidade de Alagoas, cujo e-mail continha carta de apresentação da pesquisa e dos pesquisadores, bem como um link para um formulário on-line contendo o questionário da pesquisa. Geograficamente, o estudo limitou-se ao estado de Alagoas.

Objetivando obter um maior grau de homogeneidade dos participantes da pesquisa, foram selecionados os dados oriundos de escritórios de contabilidade e excluídas as respostas fornecidas por contadores autônomos e/ou empregados de organizações públicas ou privadas.

Antes da aplicação definitiva da pesquisa foi realizado um pré-teste para verificar a clareza das questões e a existência de perguntas desnecessárias a fim de, posteriormente, se fazer as devidas alterações. 0 pré-teste foi realizadopessoalmente pelos pesquisadores em duas organizações contábeis. Após as alterações, o questionário foi enviado por mala-direta. Ao todo se obteve 89 questionários respondidos e que atendiam aos requisitos preestabelecidos.

0 tratamento estatístico dos dados aplicou técnicas de análise descritiva e testes de hipótesesnão paramétricos (teste $\chi 2 \mathrm{e}$ teste exato de Fisher). 


\section{ANÁLISE DOS DADOS}

0 perfil dos respondentes da pesquisa mostra a predominância do sexo masculino $(66,3 \%)$ e da faixa etária de 31 anos ou mais $(83,1 \%)$ sendo que $43,8 \%$ dos pesquisados já ultrapassa os 40 anos. Foi evidenciada uma tendência dos pesquisados em parar os estudos no nível de especialização. Apenas 2 respondentes informaram ter cursado mestrado ou doutorado. Esse resultado já era de se esperar devido as características educacionais do estado de Alagoas, unidade da federação que apresenta baixos índices de educação, quando comparados com o de outras regiões do Brasil. 0 estado não possui oferta de cursos de pós-graduação stricto sensu nas áreas de administração e contabilidade. Essa situação obriga quem deseja realizar tais cursos a deslocar-se até outros estados e reduzir substancialmente suas atividades profissionais, ou até mesmo encerrá-las. Quanto ao tempo de existência das empresas, os dados da amostra pesquisada mostram que $47,7 \%$ delas têm menos de 10 anos de atividade. Não foi identificada relação entre o tempo de existência dessas empresas e a titulação dos contabilistas.

Um dos interesses da investigação foi identificar os tipos de serviços ofertados pelos profissionais pesquisados aos seus clientes. Esse interesse surgiu da curiosidade sobre se quem oferta determinado serviço (logo possui o conhecimento para tal) também o utiliza (Tabela 1).

Como o foco da pesquisa foi a utilização de artefatos gerenciais, na análise dos dados buscou-se identificar quem oferta, ou não, serviços de contabilidade gerencial. Os dados da pesquisa mostram que $54,8 \%$ dos respondentes ofertam tais serviços. Comparando-se essas respostas com a maior titulação dos participantes da pesquisa, verificou-se que não há relação estatisticamente significativa entre as variáveis, logo o fato de cursar uma pósgraduação não contribui para aumentar, ou diminuir, a oferta de informações gerenciais (ver Tabela 1).

A percepção que o mercado (notadamente micro e pequenas empresas que utilizam serviços de contabilidade terceirizados) ainda tem dos contadores, como meros expedidores de guias de tributos e cumpridores das

Tabela 1 - Escolaridade do profissional vs. Serviços ofertados

\begin{tabular}{|c|c|c|c|c|c|}
\hline \multicolumn{2}{|c|}{ Discriminação } & \multicolumn{3}{c|}{ Serviços ofertados } \\
\cline { 4 - 6 } & & $\begin{array}{c}\text { Não oferece } \\
\text { contabilidade } \\
\text { gerencial }\end{array}$ & $\begin{array}{c}\text { Oferece } \\
\text { contabilidade } \\
\text { gerencial }\end{array}$ & Total \\
\hline Escolaridade & Até o nível superior & Frequência & 27 & 31 & 58 \\
\hline & & Percentual & 32,1 & 36,9 & 69,0 \\
\hline & Especialista ou mais & Frequência & 11 & 15 & 26 \\
\hline & & Percentual & 13,1 & 17,9 & 31,0 \\
\hline & Total & Frequência & 38 & 46 & 84 \\
\hline & & Percentual & 45,2 & 54,8 & 100,00 \\
\hline
\end{tabular}

Fonte: Dados da pesquisa X2(p-value): 0,7179 
obrigações tributárias acessórias, levou ao questionamentode como os respondentes percebiam quais fatores os diferenciavam de seus concorrentes de forma a conquistar mais clientes.

Utilizando-se uma escala tipo Likert de quatro níveis, calculou-se a média das respostas a fim de encontrar tais fatores (ver Tabela 2). Verificou-se que os resultados obtidos corroboram com os encontrados por Anjos, Miranda e Silva (2010) que em sua pesquisa verificaram que gestores de cooperativas também afirmam que o preço dos serviços não é critério relevante para escolha do profissional. 0 estudo desses pesquisadores apresenta os mesmos três principais critérios, entretanto, em ordem diferente (experiência, conhecimento de legislação tributária, qualidade dos serviços).

A análise dos resultados chama a atenção para evidências de que os contadores, mesmo afirmando que entregam relatórios gerenciais, percebem a educação continuada (cursar pós-graduação) e a elaboração de informações gerenciais como os fatores menos decisivos para que seus clientes os escolham, o que parece um contrassenso, pois o fornecimento de informações que possam auxiliar a gestão, aparentemente, deveria ser algo de maior relevância.

0 que foi evidenciado pode levar a outras discussões como: conhecer legislação tributária é percebido como mais importante que fornecer relatórios gerenciais; e o fato de o contador continuar seus estudos além do bacharelado, não ser percebido como algo que possa contribuir para melhorar os serviços que presta.

Essa percepção pode ser oriunda do fato observado de que poucos possuem titulação em nível de mestrado ou doutorado, entretanto, este estudo não é suficiente para se chegar a uma conclusão quanto a isto.

Os resultados da pesquisa corroboram ainda com os que foram encontrados por Caneca (2008), que verificou que um dos critérios julgados menos importantes é o preço cobrado pelos serviços, ao passo que a experiência do profissional, além do seu conhecimento sobre legislação tributária estão entre os mais relevantes. Isto mostra

Tabela 2 - Critérios utilizados para a escolha do contador, segundo a percepção dos entrevistados

\begin{tabular}{|l|c|c|}
\hline \multicolumn{1}{|c|}{ Critério } & Frequência & Média \\
\hline Qualidade dos serviços & 84 & 3,82 \\
\hline Experiência do contador & 83 & 3,74 \\
\hline $\begin{array}{l}\text { Conhecimento de legislação } \\
\text { tributária }\end{array}$ & 84 & 3,71 \\
\hline $\begin{array}{l}\text { Pontualidade na entrega dos } \\
\text { relatórios }\end{array}$ & 85 & 3,48 \\
\hline Nível de tecnologia & 85 & 3,29 \\
\hline Indicação de amigos & 83 & 3,09 \\
\hline Elaborar relatórios gerenciais & 84 & 2,88 \\
\hline Preço dos serviços & 84 & 2,71 \\
\hline Fato de ser pós-graduado & 80 & \\
\hline
\end{tabular}

Fonte: Dados da pesquisa 
Tabela 3 - Importância da entrega de relatórios gerenciais vs. serviços ofertados

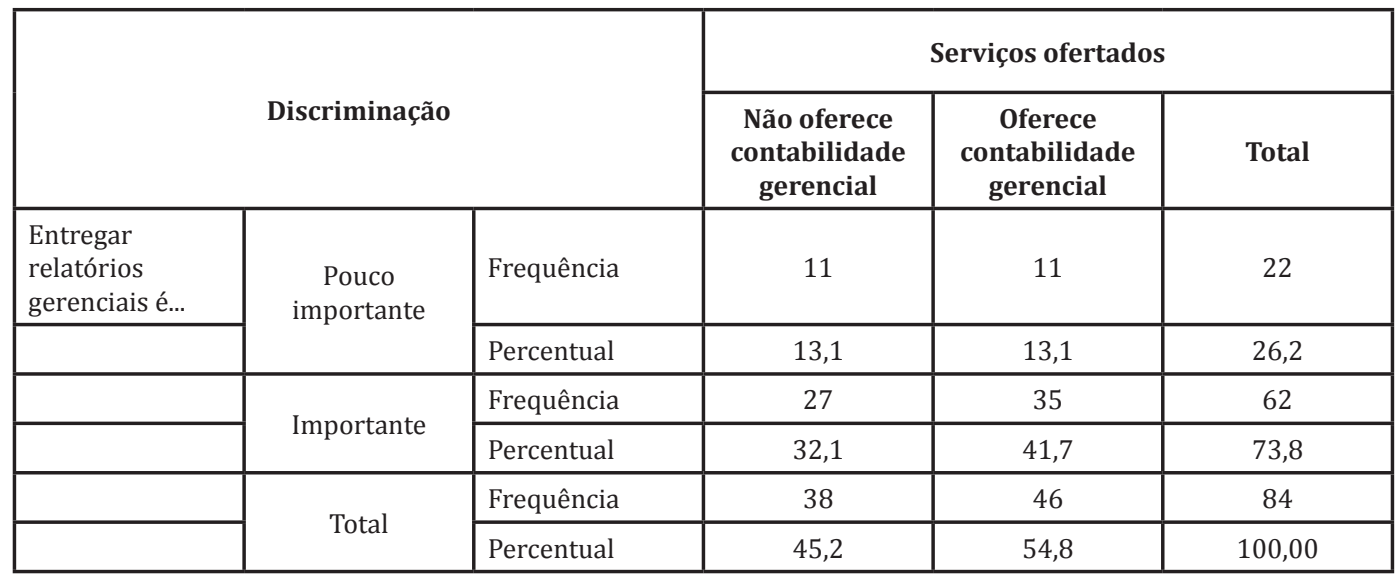

Fonte: Dados da pesquisa

X2(p-value): 0,6014

que a estruturação das organizações contábeis, conforme exposto por Pereira (2005), ainda leva bastante em conta o cumprimento das obrigações fiscais e tributárias dos clientes.

A partir desses resultados, buscou-se analisar se os contadores que afirmaram ofertar serviços de contabilidade gerencial para seus clientes consideram este um critério relevante para sua contratação. A análise mostra que mesmo não havendo relação estatisticamente significativa entre as variáveis, aqueles que consideram a apresentação de informações gerenciais um critério útil para que o cliente opte por sua contratação, ofertam mais este serviço do que os demais contabilistas (ver Tabela 3).

Conforme pode ser visto pelos dados apresentados na Tabela 4, a maioria dos respondentes da pesquisa não utiliza nenhum critério contábil para analisar o preço dos serviços ofertados. Apenas uma minoria utiliza artefato de custos.

Uma questão aberta, colocada no questionário da pesquisa, permitiu que os respondentes apontassem quais métodos consideram mais comuns para formar preços. Verificou-se que o conjunto entre

Tabela 4 - Método utilizado na formação do preço dos serviços prestados pelos pesquisados

\begin{tabular}{|l|c|c|}
\hline \multicolumn{1}{|c|}{ Critério } & Frequência & Percentual \\
\hline Diferenciação (percepção do cliente) & 31 & 37,8 \\
\hline Preço meta (concorrência) & 13 & 15,9 \\
\hline Diferenciação (percepção do cliente) + Preço meta (concorrência) & 9 & 11,0 \\
\hline Formulário de pesquisa sobre o cliente & 4 & 4,9 \\
\hline $\begin{array}{l}\text { Diferenciação (percepção do cliente) + Formulário de pesquisa sobre o } \\
\text { cliente }\end{array}$ & 4 & 4,9 \\
\hline Custeio direto + Mark-up & 3 & 3,7 \\
\hline Outros (considerando informações contábeis) & 21 & 25,0 \\
\hline
\end{tabular}

Fonte: Dados da pesquisa 
o faturamento do cliente, seu regime de tributação, porte e quantidade de funcionários é o principal critério, pois são indicadores da "quantidade de serviços" que terão, já que permite uma estimação do total de obrigações tributárias e patronais às quais o cliente estaria sujeito.

Sabe-se que o preço é efetivamente formado pelo mercado, entretanto, como o não conhecimento dos custos de servir pode ter interferência negativa nos resultados da entidade, e até mesmo em sua continuidade, eles devem ser conhecidos e avaliados. Uma pesquisa desenvolvida por Lopes et al. (2007) mostrou que os escritórios contábeis de João Pessoa - PB utilizam, como critério de formação de preço dos serviços, principalmente, a percepção do cliente (45,5\% dos respondentes) e custeio direto + mark-up (27,3\% dos respondentes). Esta investigação verificou que, em Alagoas, a diferenciação é também o principal critério, entretanto, poucos utilizam instrumentos contábeis para tomar tal decisão.

Para se identificar se os pesquisados utilizam algum método de custeio para a tomada de outras decisões, incluiu-se como resposta a esta variável, o feeling do gestor. Apesar da literatura de custos não abordar isso como um sistema de custeio, a experiência profissional dos pesquisadores, além de estudos na área de gestão e empreendedorismo em micro e pequenas empresas, possibilitam perceber tal prática na tomada de decisão (LUCENA, 2004; LOPES et al., 2007; UMBELINO, 2008; CANECA, 2008). Como pode ser verificado na Tabela 5, 27\% afirmaram não utilizar nenhum método de custeio para decisão enquanto, $31,5 \%$ utilizam seu feeling. Isso mostra que $58,5 \%$ dos elementos da amostra não utilizam método algum de custeio no processo decisório em suas organizações. Pode ser uma deficiência dos profissionais na análise da eficiência da entidade, pois não sabem se há desperdícios ou possibilidades de reduzir custos mantendo, pelo menos, os níveis atuais de receita e, consequentemente, melhorando seus resultados econômicos e financeiros. 0 estudo conduzido por Lopes et al. (2007), em João Pessoa, mostra que a maioria das empresas utiliza o custeio por absorção (45,5\%) ou variável $(36,4 \%)$, evidenciando que na decisão quanto ao critério de formação de preço é costumeira a utilização de métodos formais para fundamentar essa decisão. Em Alagoas, esta pesquisa identificoumaior tendência para os critérios não formais.

Quanto à utilização de indicadores gerenciais na gestão de seus negócios, os pesquisados mostraram que 38\% deles não selecionam seu portfólio através de indicadores gerenciais e 78\% afirmaram conhecer os riscos operacionais inerentes da operação de seus negócios.

Em relação ao conhecimento e análise da capacidade de geração de caixa na empresa, observou-se que $42,1 \%$ responderam de forma negativa (ver Tabela 6). Relacionando essa informação com o fato de os entrevistados separarem seus

Tabela 5 - Método de custeio para decisão

\begin{tabular}{|l|c|c|}
\hline Discriminação & Frequência & Percentual \\
\hline Feeling & 28 & 31,5 \\
\hline Variável & 21 & 23,6 \\
\hline Absorção & 10 & 11,2 \\
\hline ABC & 6 & 6,7 \\
\hline Nenhum & 24 & 27,0 \\
\hline Total & 89 & 100,0 \\
\hline \multicolumn{3}{|c|}{ Fonte: Dados da pesquisa }
\end{tabular}


Tabela 6 - Conhece e analisa capacidade de gerar caixa vs.Separa clientes por nível de retorno

\begin{tabular}{|c|c|c|c|c|c|}
\hline Diccriming & & & Separa c & tes por níve & retorno \\
\hline DISCR IIIIIIa & & & Discordo & Concordo & Total \\
\hline & Não & Frequência & 22 & 13 & 35 \\
\hline & & Percentual & 26,5 & 15,6 & 42,1 \\
\hline Conhece e analisa capacidade de gerar & Sim & Frequência & 16 & 32 & 48 \\
\hline caixa & & Percentual & 19,3 & 38,6 & 57,9 \\
\hline & Total & Frequência & 38 & 45 & 83 \\
\hline & & Percentual & 45,8 & 54,2 & 100,00 \\
\hline Nível de significância do teste & & & 0,007 & & \\
\hline
\end{tabular}

Fonte: Dados da pesquisa

X2(p-value): 0,008

Teste exato de Fisher (p-value): 0,007

clientes por nível de retorno, percebeu-se que àqueles que analisam a capacidade de gerar caixa do negócio também separam seus clientes por nível de retorno. Os testes $\chi 2$ e exato de Fisher mostraram significância nos relacionamentos, o que seria de se esperar, pois analisar os clientes dessa forma é uma das ferramentas para se conhecer a capacidade de geração de caixa.

Ao se comparar as respostas referentes à utilização de algum sistema de custeio para decisão com o fato de se analisar o desempenho por centros de resultado, verificou-se que a análise por centros de resultado é mais comum entre aqueles que utilizam algum método de custeio para tomada de decisão, conforme pode ser verificado na Tabela 7. A utilização dos testes $\chi 2$ e exato de Fisher mostrou a existência de significância nos relacionamentos do conhecimento e análise da capacidade de gerar caixa com a utilização de custeio para a tomada de decisão.

Questionados se conhecem e entendem a utilização e as informações geradas pelo Balanced Scorecard (8 pesquisados não responderam o questionamento) a maioria dos respondentes $(61,7 \%)$ informou não conhecer, ou saber utilizar, tal ferramenta (Tabela 8). O BSC foi selecionado como

Tabela 7 - Conhece e analisa capacidade de gerar caixa vs. Custeio para decisão

\begin{tabular}{|c|c|c|c|c|c|}
\hline & \multirow{2}{*}{\multicolumn{2}{|c|}{ Discriminação }} & \multicolumn{3}{|c|}{ Custeio para decisão } \\
\hline & & & Não utiliza & Utiliza & Total \\
\hline \multirow{6}{*}{$\begin{array}{l}\text { Analisa o } \\
\text { desempenho } \\
\text { por centros de } \\
\text { resultado }\end{array}$} & Não & Frequência & 27 & 8 & 35 \\
\hline & & Percentual & 32,5 & 9,7 & 42,2 \\
\hline & Sim & Frequência & 19 & 29 & 48 \\
\hline & & Percentual & 22,9 & 34,9 & 57,8 \\
\hline & Total & Frequência & 46 & 37 & 83 \\
\hline & & Percentual & 55,4 & 44,6 & 100,00 \\
\hline
\end{tabular}

Fonte: Dados da pesquisa

X2(p-value): 0,0007 - Teste exato de Fisher (p-value):0,0008 
Tabela 8 - Conhecimento do BSC

\begin{tabular}{|l|l|c|c|c|c|}
\hline \multicolumn{2}{|c|}{ Discriminação } & Frequência & \% & \% Válido & \% Acumulado \\
\hline \multirow{3}{*}{$\begin{array}{l}\text { Respostas } \\
\text { válidas }\end{array}$} & Não & 50 & 56,2 & 61,7 & 61,7 \\
\cline { 2 - 7 } & Sim & 31 & 34,8 & 38,3 & 100,0 \\
\cline { 2 - 7 } & Total & 81 & 91,0 & 100,0 & \\
\hline Não respondeu & 8 & 9,0 & & & \\
\hline Total & 89 & 100,0 & & & \\
\hline
\end{tabular}

Fonte: Dados da pesquisa

exemplo de um artefato contemporâneo pela sua amplitude de aplicações, além da quantidade de estudos que têm sido publicados nesta temática. 0 resultado mostra que esta ferramenta que tem mostrado sua importância não só na contabilidade, mas em outras áreas também, ainda não é de larga utilização entre os pesquisados.

\section{CONCLUSÕES}

A pesquisa em tela procurou responder ao seguinte questionamento: estariam os contadores utilizando artefatos contábeis gerenciais na gestão de seus próprios negócios?

Com base na análise dos resultados da pesquisa, verificou-se que os contadores, apesar de afirmarem que fornecem informação gerencial para seus clientes, não a consideram um diferencial de mercado para conquistar novos clientes. Não entendem, também, que o fato de ser pós-graduado pode melhorar seus serviços de forma a aumentar sua participação no mercado. Por outro lado, foi afirmado que alguns dos principais critérios para que uma empresa contrate os serviços prestados pelo seu escritório são sua experiência e conhecimento da legislação tributária.

Verificou-se também que para a formação de preço de seus serviços não costumam ser levados em consideração os custos desta prestação. A percepção de quanto o cliente está disposto a pagar $(37,8 \%)$, o preço da concorrência $(15,9 \%)$ e a combinação de ambos (11\%) são os principais métodos utilizados, enquanto apenas 28,7\% dos participantes da pesquisa dizem utilizar algum critério de custeio para analisar os preços ofertados.

Observou-se ainda que a maioria $(58,5 \%)$ dos contadores também não utiliza sistemas de custeio para tomada de decisão. Por outro lado, eles afirmam utilizar indicadores gerenciais na gestão de seus negócios. Dentre os apresentados na pesquisa os mais citados foram os relacionados à geração de caixa ou capital de giro. No entanto, ferramentas mais contemporâneas como o Balanced Scorecard são menos conhecidas e utilizadas pelos respondentes. Isso evidencia que a utilização de artefatos gerenciais contemporâneos, que não levam em conta apenas informações financeiras, mas também físicas e patrimoniais, ainda não são bem utilizadas pelos contadores na gestão de seus próprios negócios.

Ressalte-se que definir quais informações são úteis para a gestão é algo que deve considerar a cultura, formação e comportamento de seu usuário, logo a pesquisa, ao perceber que os contadores não 
têm utilizado artefatos contábeis gerenciais, tem como limitação apresentar uma quantidade restrita de ferramentas, cabendo a realização de pesquisas qualitativas que entendam melhor essa questão.

É importante salientar que o pequeno tamanho da amostra utilizada e a forma como foram realizados os procedimentos amostrais de coleta de dados, ao se utilizar o método de conveniência, impossibilita a generalização dos resultados para todo o universo de contadores alagoanos.

A pesquisa pelo seu caráter mais de cunho exploratório, serve como passo inicial para pesquisas mais amplas que aprofundem os temas abordados e clarifiquem melhor 0 comportamento dos profissionais contábeis quanto à utilização de artefatos gerenciais.

Como sugestão para pesquisas futuras, pesquisadores interessados poderiam ampliar a amostra, não apenas em quantidade, mas também geograficamente para identificar se há alterações no comportamento nas diferentes regiões do país, bem como poderiam também utilizar técnicas qualitativas para aprofundar o entendimento acerca dos motivos que levam a tal comportamento.

\section{REFERÊNCIAS}

ADRIANO, Nayana A. et al. A tecnologia da informação das empresas prestadoras de serviços contábeis: um estudo realizado na cidade de Pesqueira/PE. In: CONGRESSO INTERNACIONAL DE CUSTOS, 10, 2007, Lyon.Anais eletrônicos... Lyon: IIC, 2007. Disponível em:<http://www.intercostos.org/documentos/Queiroga.pdf>.Acesso em: 23jan.2011.

ANJOS, Luiz C. M.; MIRANDA, L. C.;SILVA. Utilização de informações contábeis em cooperativas: são os contadores necessários? In: SEMINÁRIO UFPE DE CIÊNCIAS CONTÁBEIS, 4, 2010, Recife. Anais eletrônicos...Recife: UFPE, 2010.1 CD-ROM.

CANECA, Roberta L. Oferta e procura de serviços contábeis para micro, pequenas e médias empresas: um estudo perceptivo das percepções dos empresários e contadores. 2008. 178 f. Dissertação (Mestrado em Ciências Contábeis) -Universidade de Brasília, Universidade Federal de Pernambuco, Universidade Federal da Paraíba e Universidade Federal do Rio Grande do Norte, Recife, 2008.

CONSELHO FEDERAL DE CONTABILIDADE.Consulta nacional de ativos. Disponível em:<http://www.cfc.org.br> Acesso em: 17jan.2011.

Resolução CFC no 1.166/09- Dispõe sobre o registro cadastral das organizações contábeis. 2009. Disponível em:<http://www.cfc.org.br>. Acesso em: 17jan.2011.

Resolução CFC no 1.121/08 - aprova a NBC T 1 - estrutura conceitual para a elaboração e apresentação das demonstrações contábeis.2008. Disponível em:<http://www.cfc.org.br>. Acesso em: 17jan.2011.

DUTRA, Ivan de Souza.0 perfil do empreendedor e a mortalidade de micro e pequenas empresas londrinenses. 2002. 125f. Dissertação (Mestrado em Administração) -Universidade Estadual de Londrina,Londrina, 2002.

DRUCKER, Peter F. Innovation and entrepreneurship.New York: Harper Business, 1993.

FREZATTI, Fábio. Management accounting profile of firms located in Brazil: a field study. Revista de Administração Contemporânea, v. 9, 2 ed. especial, p. 147-165, 2005.

GARRISON, Ray H; NOREEN, Eric W; BREWER, Peter C.Contabilidade gerencial. 11 ed. Rio de Janeiro: LTC, 2007.

KAM, Vernom. Accounting theory. 2 ed. New York: John Wiley \& Sons, 1990.

KANITZ, Stephen C. Controladoria: teoria e estudo de casos. São Paulo: Pioneira, 1977.

LAUDON, Kenneth C.; LAUDON, Jane P. Sistemas de informações. 4. ed. Rio de Janeiro: LTC, 1999. 
LOPES, Alexandre Broedel; MARTINS, Eliseu.Teoria da contabilidade:uma nova abordagem. São Paulo: Atlas, 2005.

LOPES, Jorge E. G. et al. A utilização das informações de custos na formação de preços: as empresas de serviços contábeis. In: SEMINÁRIO DE CIÊNCIAS CONTÁBEIS FURB, 3, 2007, Blumenau. Anais eletrônicos...Blumenau: FURB, 2007. Disponível em: <https://www.furb.br/especiais/download/286119-396539/007\%20-\%20Utilizacao\%20 das\%20informacoes\%20de\%20custos.pdf>. Acesso em: 17 jan. 2011.

LUCENA, Wenner G. L. Uma contribuição ao estudo das informações contábeis geradas pelas micro e pequenas empresas localizadas na cidade de Toritama no agreste pernambucano. Dissertação (Mestrado em Ciências Contábeis) -Universidade de Brasília, Universidade Federal de Pernambuco, Universidade Federal da Paraíba e Universidade Federal do Rio Grande do Norte, Recife, 2004.

MAGALHÃES, Antônio de Deus F.; LUNKES, Irtes C. Sistemas contábeis: o valor informacional da contabilidade nas organizações. São Paulo: Atlas, 2000.

MARRIOT, Neil; MARRIOT, Pru. Professional accountants and the development of a managerial accounting service for the small firm: barriers and possibilities.Management AccountingResearch, n. 11, n. 4, p. 475-492, 2000 .

MARTINS, Vidigal F. A necessidade do planejamento estratégico nas organizações contábeis. Contabilidade Vista \&Revista, v. 12, n. 2, p. 73-80, 2001.

MCCLELLAND, David C. The achieving society. Princeton: D. Van Nostrand, 1961.

McGEE, J.; PRUSAK, L. Gerenciamento estratégico da informação:aumente a competitividade e a eficiência de sua empresa utilizando a informação. Rio de Janeiro: Campus, 1995.

MEIRELLES, Dimária S. 0 conceito de serviço. Revista de Economia Política, v. 26, n. 1, p. 119-136, 2006.

MIRANDA, Luiz Carlos et al. Demanda por serviços contábeis pelos micro e pequenos supermercados: são os contadores necessários? In: CONGRESSO BRASILEIRO DE CUSTOS, 16., 2007, João Pessoa. Anais eletrônicos... João Pessoa: CBC, 2007. 1 CD-ROM.

NAIR, K. R. G.; PANDEY, Anu. Characteristics of entrepreneurs: an empirical analysis. The JournalofEntrepreneurship, v. 15, n. 1, p. 47-61, 2006.

OLIVEIRA, A. M. Informações contábeis-financeiras para empreendedores de empresas de pequeno porte 2001. Dissertação (Mestrado em Controladoria e Contabilidade) - Universidade de São Paulo, São Paulo, 2001.

OYADOMARI, José Carlos et al. Fatores que influenciam a adoção de artefatos de controle gerencial nas empresas brasileiras: um estudo sob a ótica da teoria institucional. Revista de Contabilidade e Organizações, v. 2, n. 2, p. 55-70, 2008.

PEREIRA, Mário C. C. Empresas de serviços contábeis: condicionantes estratégicas para uma atuação empreendedora. Pensar Contábil, v. 7, n. 29, 2005

PORTER, Michael E. Estratégia competitiva: técnicas para análise de indústrias e da concorrência. 7 ed. Rio de Janeiro: Campus, 1986.

SCHUMPETER, Joseph A. The theory of economic development. New York: OxfordUniversity Press, 1961.

SOUTES, Dione O. Uma investigação do uso de artefatos da contabilidade gerencial por empresas brasileiras. 116 f. Dissertação (Mestradoem Controladoria e Contabilidade) - Universidade de São Paulo, São Paulo, 2006.

STROEHER, A. M.; FREITAS, Henrique. Identificação das necessidades de informações contábeis de pequenas empresas para tomada de decisão organizacional. In: CONGRESSO INTERNACIONAL DE GESTÃO DA TECNOLOGIA E SISTEMAS DE INFORMAÇÃO, 3, 2006, São Paulo. Anais eletrônicos... São Paulo: FEA/USP, 2006, p. 233, 1 CD-ROM.

THOMÉ, Irineu. Empresas de serviços contábeis:estrutura e funcionamento. São Paulo: Atlas, 2001.

UENO, Rodrigo B.; CASA NOVA, Silvia P. Um estudo sobre a percepção do micro e pequeno empresário sobre a importância da contabilidade no processo de tomada de decisão. In: SEMINÁRIO DE ADMINISTRAÇÃO, 9, 2006, São Paulo. Anais eletrônicos... Disponível em: <www.ead.fea.usp.br/Semead/9semead/resultado_semead/ trabalhosPDF/377.pdf>. Acesso em: 15 fev. 2009. 
UMBELINO, Wesley Serbim. Avaliação qualitativa do desequilíbrio da oferta e demanda de serviços contábeis nas micros, pequenas e médias empresas da grande Recife. 2008. 78 f. Dissertação (Mestrado em Ciências Contábeis) -Universidade de Brasília, Universidade Federal de Pernambuco, Universidade Federal da Paraíba e Universidade Federal do Rio Grande do Norte, Recife, 2008.

\section{Luiz Carlos Marques dos Anjos}

Mestre em Contabilidade pela Universidade Federal de Pernambuco. Professor Assistente na Universidade Federal de Alagoas Endereço eletrônico: Icanjos@feac.ufal.br

Currículo Lattes: http://buscatextual.cnpq.br/buscatextual/visualizacv.do?id=K4137660Y6

\section{Paulo da Cruz Freire dos Santos}

Doutor em Engenharia da Produção pela Universidade Federal de Santa Catarina. Professor Associado na Universidade Federal de Alagoas.

Endereço eletrônico: admpaulodacruz@gmail.com

Currículo Lattes: http://buscatextual.cnpq.br/buscatextual/visualizacv.do?id=K4792540D7

\section{Luiz Carlos Miranda}

Ph.D. pela University of Illinois. Professor Adjunto e Coordenador do Programa de Pós-Graduação em Ciências Contábeis da Universidade Federal de Pernambuco.

Endereço eletrônico: Ic-miranda@uol.com.br

Currículo Lattes: http://buscatextual.cnpq.br/buscatextual/visualizacv.do?id=K4781614U7

\section{Daniel José Cardoso da Silva}

Mestre em Contabilidade pela Universidade Federal de Pernambuco. Professor Assistente na Universidade Federal de Alagoas. Endereço eletrônico: danielcardoso@feac.ufal.br

Currículo Lattes:http://buscatextual.cnpq.br/buscatextual/visualizacv.do?id=K4261260P1

\section{Rommel de Santana Freire}

Doutorando em Administração na Universidade Federal de Pernambuco. Professor Assistente na Universidade Federal da Paraíba.

Endereço eletrônico: rommelfreire@uol.com.br

Currículo Lattes:http://buscatextual.cnpq.br/buscatextual/visualizacv.do 
Luiz Carlos Marques dos Anjos, Paulo da Cruz Freire dos Santos, Luiz Carlos Miranda, Daniel José Cardoso da Silva, Rommel de Santana Freire 